\title{
Analyzing the Magnitude of Global Epidemiological Transition in Sub- Saharan Africa: A Need to Review the Current Healthcare Management Approach
}

\author{
Abiodun Bamidele Adelowo \\ Department of Public health, Texila American University, Guyana
}

\begin{abstract}
Since after World War II, the world has been grappling with the grumbling rising prevalence and economic burden of non-communicable diseases (NCDs). The rise of these chronic diseases has reached an epidemic proportion and a melting point in many communities of the world. This has been made worse by the recent COVID-19 pandemic. While the world is still battling this debilitating reality, a more gruesome scenario is evolving in low-income and Middle-Income Countries (LMICs). Although these countries account for the highest poverty index in the world, they also account for a disproportionately higher burden of NCDs. More than $80 \%$ of NCD-related deaths are presently recorded among the LMICs. Ironically, although most sub-Saharan Africa (SSA) countries can be categorized as LMICs, yet communicable diseases (CDs) still constitute the highest disease burden in this region. However, based on global projections, SSA may soon lose this 'advantage' and may become the region with the highest burden of NCDs by the year 2030. If the present trajectory is left unshattered, the resulting heavy double burden of CDs and NCDs will likely crumble the already fragile economy of most SSA countries and tilt the region into an unprecedented recession. A critical review of the present disease-centered healthcare management approach and adoption of a more evidence-based health promotion-centered management approach may be vital in salvaging the situation. This article briefly reviewed the global epidemiologic transition, compared the disease- and health promotion-centered healthcare models, and made a case for a change in health management strategy in SSA.
\end{abstract}

Keywords: Disease-centered approach, Epidemiological transition, Health promotion-centered approach, lifestyle modification, Non-communicable Diseases Risk factors, sub-Saharan Africa.

\section{Introduction}

For many centuries, communicable diseases (CDs) accounted for the highest global causes of morbidity and mortality. A turning point was, however, noticed during the first half of the $20^{\text {th }}$ century. Precisely after the Second World War, the high-income industrialized countries of the world made major breakthroughs against infectious and childhood diseases, primarily through advances in pharmacotherapy, public health vaccination, and sanitation. These measures led to a drastic and considerable decrease in the prevalence of CDs and maternal and infant mortalities, with the consequential increase in life expectancy to middle and late adult life, a process which medical science significantly perfected over the next 100 years [1-3].

As however noticed, the relative healthcare stability that was achieved through the effective fight against communicable and nutrition-related diseases seems to have created a vacuum, which had been filled up with a rather more challenging group of chronic diseases - the noncommunicable diseases (NCDs). The global epidemiological transition from CDs to NCDs started in the middle of the $20^{\text {th }}$ century, with heart diseases (and many other NCDs) virtually unknown until the 1920s, when the cases of 
atherosclerotic heart diseases were first comprehensively documented [1-3]. However, in just a few decades after that, the burden of NCDs has risen significantly, spreading very fast from America to Europe, Asia, and to the rest of the world $[1,4]$. For example, atherosclerosisrelated diseases were so rare in Japan in the 1950s and 70s that the University of Tokyo had to be importing atherosclerotic coronary artery specimens from John Hopkins University in Baltimore for practical demonstration during medical training. A few decades later, due to the epidemiological transition in Asia, Japan soon had enough local cases of coronary artery diseases [1].

By the $21^{\text {st }}$ century, NCDs had clearly become the leading global causes of morbidity and mortality. $70 \%$ of all yearly deaths worldwide are now attributed to NCDs [6]. Out of the 57 million deaths recorded globally in 2016, 41 million or $73 \%$, were due to NCDs, mainly from cardiovascular diseases - CVDs (17.9 million deaths, accounting for $44 \%$ of all NCD deaths and $31 \%$ of all global deaths); cancers ( 9 million deaths, $22 \%$ of all NCD deaths and $16 \%$ of all global deaths); chronic obstructive respiratory diseases - COPD (3.8 million deaths, $9 \%$ of all NCD deaths, and $7 \%$ of all global deaths); and diabetes mellitus - DM (1.6 million deaths, 4\% of all NCD deaths and $3 \%$ of all global deaths) [7], which means that in the same year, the mortality rate from NCDs more than doubled the mortality rates from all other causes combined (including deaths from HIV/AIDS, maternal mortality, malaria, terrorism, war, and natural disasters).

NCDs are also the leading cause of global premature adult death (deaths occurring in those aged 30-69 years), the most productive age group in the world. It accounts for about $75 \%$ of annual global premature adult death [7]. The prevalence of NCDs and related mortality will likely continue to increase globally, with the greatest rise and impact expected to be seen and felt in the low- and middle-income countries (LMICs) [7]. The recent COVID-19 pandemic has added another dimension to the epidemiology and pathophysiology of NCDs. The incidence, progression, hospitalization, and case-fatality rates of COVID-19 cases have been noticed to increase in the presence of underlying NCDs (mainly CVDs, DM, COPD, and some cancers) [8]. Furthermore, the development of COVID-19 has also been associated with rapid clinical progression of most NCDs, with increased mortality from NCD-related complications [9]. By implication, any COVID19 preventive and treatment effort, without due consideration for the prevention and control of NCDs, will likely be inadequate in controlling the COVID-19 pandemic.

\section{The Disproportionate Burden of Non- Communicable Diseases in the LMICs and SSA}

A rather worrisome development is the disproportionate impact of NCDs on the Lowand Middle-Income Countries (LMIC) of the world. Although this group of countries constitutes the poorest nations in the world, NCDs presently strike the hardest on these nations [2]. What were once viewed as "diseases of affluence" have now encroached deep into the fabrics of the LMICs, up to an epidemic proportion in most of these nations [10-12]. More than two-thirds of all cancer deaths and nearly $80 \%$ of all NCD-related deaths now occur annually in the LMICs $[7,13]$. Specifically, in the year 2016, $78 \%$ of all NCD deaths, and $85 \%$ of premature adult NCD deaths, were reported in the LMICs [7]. Adults living in the LMICs presently face the highest comparable risk of dying from NCDs (Low-income - 21\% and Middle-income - 23\%), which almost doubled the risk for adults in high-income countries (12\%) [7]. Likewise, in the high-income countries, the proportion of all premature adult mortality from NCDs $(25 \%)$ is almost half of that of low-income $(43 \%)$ and lower-middleincome countries (47\%) [7]. These statistics meant more than four out of every five NCDrelated deaths presently occur among the poorest 
communities of the world - an unsustainable situation that has been projected to worsen in the next few decades [13].

It has also been projected that the estimated percentage increase in global cancer incidence by the year 2030, compared with the year 2008, is expected to be greater in low- $(82 \%)$ and lower-middle-income countries (70\%) compared with the upper-middle (58\%) and high-income countries (40\%) [13]. As noticed by the World Health Organization (WHO), NCDs have now created a form of vicious cycle among the LMICs: poverty exposes the people living in LMICs to behavioral and environmental risk factors that increase their chances of developing NCDs; while in return, the costs of managing NCDs often become an important driver to the downward poverty trend in many families [13]. Consequently, NCDs presently deliver a two-punch blow to the socioeconomic growth of most LMICs. On a Macroeconomic level, the direct and indirect costs of managing NCDs cause billions of dollars in losses of national income and then shove millions of people in the microeconomy below the poverty line each and every year [13].

Paradoxically, although most countries in Sub-Saharan Africa (SSA) fall in the LMICs category, yet the present morbidity and mortality profiles in most of these countries are not exactly similar to the rest of the LMICs. Most countries that are geographically located in the south of the Sahara still have more morbidity and mortality profiles from communicable, maternal, perinatal, and nutritional conditions compared to NCDs [13]. For instance, as of the year 2016, the NCD attributable mortality rate in Nigeria (the country with the largest population in the SSA) was only $29 \%$, out of which CVDs and diabetes mellitus accounted for only $11 \%$ and $1 \%$ of the proportional mortality rate respectively [7]. Similarly, in the same year, 2016, the NCD attributable death rates in Kenya, Congo Democratic Republic, and Mali was only 37\%, $38 \%$, and 39\%, respectively, while communicable and related diseases are responsible for the larger percentage of death in each of these countries [7]. The different morbidity and mortality profiles in most SSA countries compared to the rest of LMICs and the rest of the world can be attributed to multiple factors. Some of which may include peculiar environmental, demographic, socio-economic, and healthcare system factors of the region compared to the rest of the world [14].

Table 1. Comparison of 2016 Mortality Rates from Different Countries

\begin{tabular}{|l|l|l|l|l|l|l|}
\hline & \multicolumn{2}{|l|}{$\begin{array}{l}\text { High-Income } \\
\text { Countries }\end{array}$} & \multicolumn{2}{l|}{$\begin{array}{l}\text { Low- and Middle- } \\
\text { Income Countries }\end{array}$} & $\begin{array}{l}\text { Sub-Saharan } \\
\text { African Countries }\end{array}$ \\
\hline Diseases & USA & France & India & Brazil & Nigeria & Zambia \\
\hline $\begin{array}{l}\text { All communicable, maternal, } \\
\text { perinatal, and nutritional }\end{array}$ & $5 \%$ & $6 \%$ & $26 \%$ & $14 \%$ & $63 \%$ & $61 \%$ \\
\hline All non-communicable & $88 \%$ & $88 \%$ & $63 \%$ & $74 \%$ & $29 \%$ & $29 \%$ \\
\hline - Cardiovascular & $30 \%$ & $26 \%$ & $27 \%$ & $28 \%$ & $11 \%$ & $10 \%$ \\
\hline - Cancers & $22 \%$ & $31 \%$ & $9 \%$ & $18 \%$ & $4 \%$ & $6 \%$ \\
\hline - Chronic respiratory & $9 \%$ & $6 \%$ & $11 \%$ & $6 \%$ & $2 \%$ & $2 \%$ \\
\hline - Diabetes mellitus & $3 \%$ & $2 \%$ & $3 \%$ & $5 \%$ & $1 \%$ & $1 \%$ \\
\hline
\end{tabular}

Table 1 illustrated relatively high noncommunicable disease attributable mortality rates in the selected high-income and lowmiddle-income countries (LMICs), compared to communicable, maternal, perinatal, and nutritional conditions. However, in most counties in sub-Saharan Africa, as seen in the selected countries, communicable diseases are still responsible for more deaths in this region [7]. 
The prevalence of NCDs (like CVDs, hypertension, dyslipidemia, diabetes mellitus, obesity, osteoporosis, and some types of cancer) is fast rising in the SSA region, and at its present rate, these chronic diseases may likely outpace the infectious diseases in all the SSA countries in no distant future and may cause almost threequarters as many deaths as communicable, maternal, perinatal, and nutritional conditions, and far exceed them as the most common causes of death by as early as the year $2030[13,15]$. If this happened, most countries in SSA would have lost the golden and rare opportunity to prevent or at least delay the heavy disease and economic burdens that NCDs presently pulls on most high-income countries of the world. Also, the present burden of the high prevalence of CDs would not likely have considerably abated by the year 2030 in SSA. This is especially true with the emergence and the reemergence of different communicable diseases, as seen with the COVID-19 pandemic. A double disease burden of CDs and NCDs may crumble the fragile and unstable economic system of most countries in SSA, a situation that may usher in an unprecedented economic recession on some if not all of these poorest nations of the world. Furthermore, the SSA region may not be the only region to suffer from the missed opportunity. The ripple effect of the double disease burden on SSA may likely be felt not only by other African communities but indeed by the entire interconnected global economy [13, $16]$.

The present infectious diseases-dominant disease profile in most SSA countries provides a rare window of opportunity for the global and regional political and health authorities to enact series of policies and programs to prevent and control the anticipated rise of NCDs among the SSA nations, and by so doing prevent, delay, or at least mitigate the health and economic catastrophes that a possible high burden of NCDs and CDs might have on some of these poorest countries of the world. Unfortunately, the present pace of actions and enthusiasm might not be enough to cause any significant impact in the changing disease profile in SSA. The political and health authorities in the SSA, the World Health Organisation, and other global stakeholders must do more to save Africa from the possible consequences of the rising burden of NCDs in the continent.

\section{The Root and Underlying Causes of the Evolving Epidemiological Transition in Sub-Saharan Africa}

The increasing globalization, urbanization, and industrialization have made most of the people in SSA change from their traditional agrarian lifestyle to the western style of living [17]. The traditional lifestyle and culture in most SSA are characterized by regular and often vigorous physical activity in the form of subsistence farming, hunting, traveling long distances on foot, etc. These are accompanied by sustenance on a high fiber, whole plant-based diet that is rich in vegetables, fruits, and legumes [17]. These traditional forms of lifestyle have gradually been eroded and substituted by the urban or "western lifestyles" characterized by the fast-paced, wage-earning economy and sedentary lifestyle. A situation that has resulted in an overreliance on the motorized transportation system and frequent consumption of unhealthy diets rich in refined carbohydrates, fats, and salts [17]. The economic transition in SSA has also resulted in a significant reduction in general physical activity levels, decreased hours of rest and relaxation, reduced quality and duration of sleep, and increased stress levels [17]. These conditions, in association with the rising unplanned or poorly planned and polluted urban settlements, overpopulation, aging population, and poor healthcare system, presently constitute the major root and underlying causes or determinants that are driving the environmental, socio-economic, cultural, and consequently, epidemiological changes in most countries in the south of the Sahara [12, 17, 18]. Policies and programs that target these root and underlying causes will be 
critical in slowing down the epidemiological transition in SSA.

Definitive actions must be taken now as the window of opportunity is fast closing. This is so because the prevalence of the primary and intermediate underlying risk or determinant factors for NCDs is fast rising in SSA. They are taking Nigeria (the country with the largest population in SSA) as a case study. Presently, the prevalence of hypertension, a major intermediate risk factor for most of the other NCDs, is significantly high in Nigeria and most countries in SSA. About $46.4 \%$ to $47.2 \%$ of Nigerian adults are presently hypertensive [19, 20]. Also, about $6 \%$ of Nigerians ( $\geq 15$ years) smoke tobacco daily [16]; while about $17.3 \%$, $6.6 \%$, and $29.3 \%$ of Nigerian adults usually get secondhand exposure to tobacco smoke at the workplace home, and restaurants, respectively [21]. The per capita consumption of pure alcohol in Nigeria is about 13 liters (22\% in males and $5 \%$ in females) [16], the prevalence of insufficient physical activity among Nigerians is $25 \%$ ( $22 \%$ male and $27 \%$ female), while about $80 \%$ of working-class Nigerian adults are classified as physically inactive [16, 21]. Furthermore, the Federal Ministry of Health of Nigeria opined that the consumption of fruits and vegetables is inadequate in most regions of the country, while excessive intake of salt and refined sugars is common [21].

The mean population salt intake in Nigerian adults (aged $\geq 20$ years) of $7 \mathrm{~g} /$ day is significantly high compared to other countries [16]. The prevalence of overweight and obesity among Nigerians (aged $\geq 20$ years) is $26.8 \%$ ( $24.2 \%$ in males and $29.3 \%$ in females); while the prevalence of raised total blood cholesterol $(\geq 5.0 \mathrm{mmol} / \mathrm{L}$ ) in people age $\geq 25$ years in Nigeria is $16.1 \%$ (13.6\% in males and $18.5 \%$ in females) [13]. These statistics of a high prevalence of the NCD-related risk factors in Nigeria are similar and sometimes higher in most other SSA [16]. In fact, the prevalence of hypertension in SSA can be as high as $48 \%$, obesity as high as $43 \%$, while current smoking of tobacco can be as high as 71\% [22]. These risk factors constitute a vital link in the pathophysiology of most NCDs, and their prolonged presence, either singly or combined, usually ignites a cascade of pathologic events that eventually culminate in the development of NCDs among the affected people [18]. Consequently, the present high prevalence of NCD-related risk factors among people living in SSA will likely translate to a high burden of NCDs in a few decades from now. The countries in SSA must urgently adopt a healthcare system that deliberately identifies and modify these risk factors among the people.

\section{The Need for Transition from Disease- centered to Health Promotion-centered Health Management Model}

The traditional biomedical healthcare model that constitutes the core of the medical management of diseases in Nigeria and most other SSA is a disease-centered or oriented model and seems to be inefficient in curbing the rising prevalence of chronic NCDs in the subregion. In this 'paternalistic' standard treatment model, the health professional primarily decides the appropriate course of treatment, and basically, intervene in the management of chronic NCDs at the secondary and tertiary prevention levels, with less emphasis on the patient's involvement in the primordial and primary prevention of diseases [23, 24]. The primary focus of the disease-centered traditional biomedical healthcare approach in chronic disease management is to rely on data from health screening and early diagnosis of specific diseases (like hypertension, diabetes mellitus, and cancer), to commence treatment in order to prevent or delay the clinical progression of the identified chronic diseases [25]. Except in few occasions (like cervical cancer when detected early), the biomedical model does not cure chronic NCDs, rather prevent, delay, or mitigate the clinical progression of the diseases and possible associated complications through the 
prescription of medications, surgery, radiotherapy, and the rest.

Although NCDs still constitute the highest disease burden in the developed world, some of these high-income countries have made some progress in controlling the rising trend of NCDs in their nations $[16,26]$. In fact, due to some definite interventions from some countries, the risk of dying from the four major NCDs in people aged 30 to 70 years has slightly dropped globally, from $22 \%$ in 2000 to $18 \%$ in 2016 [27]. The most important measures that explain the slight downward spiral in the prevalence of chronic diseases in some of these developed nations is not necessarily their advanced medical care or technology, rather their change of management approach from the 'diseasecentered' to the 'health promotion-centered' approach [26-30]. The health promotioncentered approach to healthcare is fast gaining traction in most regions of the world [4]. It is the process in the public health physicians, and clinicians collaborate with the people or patients to increase control over and to improve their health by focusing on a healthy lifestyle among the general population and the early risk identification and modification among the atrisk population [31]. This health promotion- centered approach, a form of a patient-centered approach, diverts the attention of clinical care from the screening and diagnosis of chronic NCDs to primarily the promotion of the wellbeing of the people while preventing or delaying the onset of the chronic diseases through comprehensive risk identification and lifestyle modification [23].

\section{Health Promotion Approach: A more Evidence-based Solution to the Rising Burden of Chronic Diseases}

Despite the gloomy future painted by the rising prevalence of NCDs, all hopes are not lost. The projected future gory disease burden and economic woos, especially on SSA nations, does not have to happen. Although in recent years, the burden of NCDs has been rising globally, so also is the knowledge and understanding of its prevention and control [17]. According to the Commonwealth Business Council, up to $80 \%$ of CVDs and type 2 diabetes mellitus (T2DM), and over a third of cancers could be prevented, and countries can reverse the advances of these diseases and achieve quick gains if the appropriate intervention approach is adopted, in which preventive and promotive measures are prioritized [18].

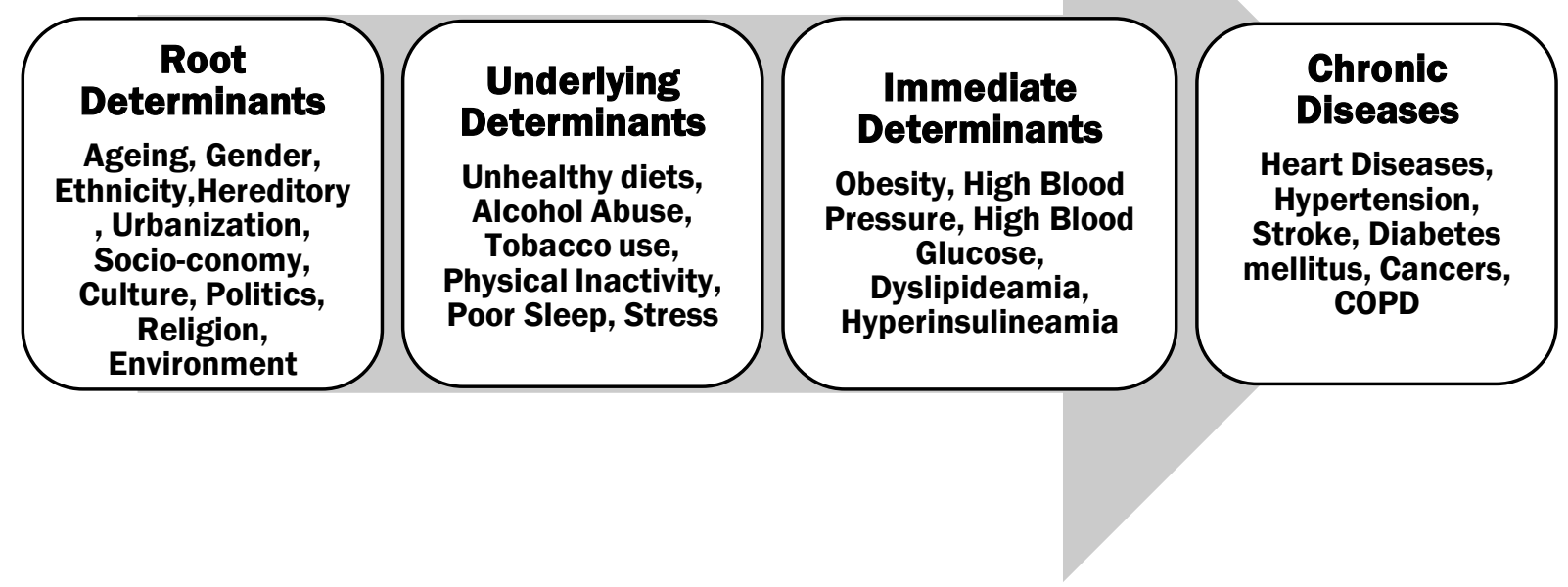

Figure 1. Causation Pathway of Most Chronic Non-Communicable Diseases 
Any intervention that effectively disrupts the pathway in Figure 1 will likely lead to a reduction in the prevalence of most chronic noncommunicable diseases.

Effective public health and clinical intervention policies, programs, or guidelines anywhere along with the disease evolution of NCDs, most importantly in the early phases, could disrupt the common pathophysiological process that characterizes most chronic NCDs and thus confer cardiovascular and metabolic protection on the affected individuals [19]. A role that health promotion-centered healthcare can effectively play. According to the WHO and United Nations, the adoption of a comprehensive preventive or health promotion-centered management approach that identifies and mitigates the implicated risk factors or determinants as earliest as possible can effectively disrupt the causative or pathophysiologic pathway of most NCDs $[4,14]$ Systematic and comprehensive control of these risk factors through evidence-based healthpromoting interventions that focus on healthy lifestyle and behavioral change among the general and at-risk population is essential and a fundamental strategy in the prevention and control of NCDs [31].

Particularly, modification of the unhealthy lifestyle-related risk factors of the at-risk population - by deliberately and effectively controlling the intermediate biological risk factors or immediate determinants like high blood lipids, high blood pressure, high blood glucose, and overweight/obesity (especially central obesity), through the effective control of the primary behavioral risk factors or underlying determinants like unhealthy/atherogenic diets, alcohol abuse, physical inactivity, tobacco use, high-stress level, and poor sleep - can have a profound and favorable impact on decreasing the incidence of initial and recurrent pathologic cardiovascular and metabolic events that are essential to the eventual development of most NCDs [20]. On a long-term basis, health promotional efforts that control the political, environmental, healthcare system, and socioeconomic root determinants of NCDs is essential in the management of the rising surge of these diseases.

Reduced morbidity and mortality rates of chronic NCDs will likely play a significant role not only in ensuring a stronger healthcare system and an improved economy among the SSA nations but may also likely significantly assist in reducing the susceptibility, severity, and casefatality rates of some infectious diseases, like COVID-19, among these nations.

\section{Conclusion}

Despite the stacking odds, winning the battle against NCDs in the SSA and the rest of the world is visible, and reversal of the trend is highly achievable, provided the healthcare management approach is comprehensive and multi-sectorial, centering on health promotion and lifestyle modification, in which there exist appropriate and adequate collaboration between government agencies, civil societies, and private sectors [18]. However, the increasing prevalence of NCD-related risk factors in SSA means the window of opportunity to strike when the iron is hottest is closing fast in this region. All hands must be on deck now; if not, a gloomy future of high disease and economic burdens await the SSA as earliest as the year 2030.

The responsibility rest on all related clinicians, public health physicians, and policymakers - government, non-governmental organizations, and politicians - to review the present healthcare management strategies and incorporate appropriate promotive healthcare management approach both in the prevention and treatment of chronic NCDs. They are also meant to sensitize and train the primary healthcare physicians and other healthcare professionals on the knowledge and skills of conducting a chronic disease risk assessment on their patients and instituting evidence-based lifestyle modification measures to reduce the identified risk factors. Accordingly, everybody must play a role and adopt adequate measures to 
tackle the rising NCD epidemics in their space of influence, with all making meaningful changes and investing adequate resources [18].

\section{Conflict of Interest}

The author declares no conflict of interest.

\section{References}

[1] Diehl H., 2011, Modern Medicine: Miracles, Medicines, Money \& Mirages, Lifestyle Medicine Institute of Loma Linda California Press, pp 1 - 14. [2] McKeown R.E., 2009, The Epidemiologic Transition: Changing Patterns of Mortality and Population Dynamics, Am J Lifestyle Med., 3(1 Suppl), 19S-26S.

https://doi:10.1177/1559827609335350.

[3] Sarukhan A., 2018, The Epidemiological Transition (or What We Died, Die and Will Die From). Barcelona Institute for Global Health (ISGlobal), Date of access: 3/2/2021. https://www.isglobal.org/en/healthisglobal/-/customblog-portlet/la-transicion-epidemiologica-o-de-quemoriamos-morimos-y-moriremos-/3098670/0.

[4] Ipsum L., 2021, The epidemiological transition. London School of Hygiene \& Tropical Medicine, Date of access: 3/2/21. https://www.futurelearn.com/info/courses/publichealth-history/0/steps/30337.

[5] Schettler G., 1983, Atherosclerosis during periods of food deprivation following world wars I and II, Preventive Medicine, 12 (1), 75 - 83. https://doi.org/10.1016/0091-7435(83)90174-3.

[6] World Health Organization, 2020, Noncommunicable diseases progress monitor 2020, World Health Organization, Date of access: 7/3/2021. https://apps.who.int/iris/handle/10665/330805.

[7] World Health Organization, 2018, Noncommunicable Diseases Country profiles 2018, World Health Organization, Date of access: 5/2/2019. https://www.who.int/nmh/publications/ncd-profiles2018/en/.

[8] Ambrosino I., Barbagelata E., Ortona E., Ruggieri A., Massiah G., Giannico O.V., et al., 2020, Gender differences in patients with COVID-19: a narrative

\section{Acknowledgement}

The author appreciates the entire faculties and staff of the Department of Human Kinetics and Health Education, University of Lagos, for their training and supports over the years.

review. Monaldi Archives for Chest Disease, 90 (1389), 318-24.

[9] Bonyan F.A., Shareef L.G., Al-waily A., Abdulrazaq A.A., and Al-Rubayee W.A., 2020, COVID-19 clinical characteristics and outcomes in 60 hospitalized Iraqi patients - Case series. Medical Science, 24(104), 2251-58.

[10] Ezzati M., Hoorn S.V., Lawes C.M.M., Leach R, James W.P.T., Lopez A.D., et al., 2005, Rethinking the "Diseases of Affluence" Paradigm: Global Patterns of Nutritional Risks in Relation to Economic Development. PLoS Medicine, 2 (5), 404-12. [11] World Health Organization, 2005, Rethinking "diseases of affluence" the economic impact of chronic diseases. World Health Organization, Date of access: 12/3/2021

https://www.who.int/chp/chronic_disease_report/me dia/Factsheet4.pdf?ua $=1$.

[12]Bloom D.E., Cafiero E.T., and Jané-Llopis E., Abrahams-Gessel S., Bloom L.R., Fathima S., et al., 2011, The Global Economic Burden of Noncommunicable Diseases. World Economic Forum, Date of access: 5/7/2018. http://www3.weforum.org/docs/WEF_Harvard_HE_ GlobalEconomicBurdenNonCommunicableDiseases _2011.pdf.

[13] World Health Organization, 2011, Global Status Report on Non-Communicable Diseases 2010. World Health Organization. Date of access: 5/7/2018. https://www.who.int/nmh/publications/ncd_report_f ull_en.pdf.

[14]Boutayeb A., 2010, The Burden of Communicable and Non-Communicable Diseases in Developing Countries. In: Preedy V.R., Watson R.R. (eds) Handbook of Disease Burdens and Quality of Life Measures, Springer, New York, NY. https://doi.org/10.1007/978-0-387-78665-0_32. 
[15] Sibai A., Tohme R.A., Mahfoud Z., Chaaya M., and Hwalla N., 2009, Non-communicable Diseases and Behavioral Risk Factor Survey: Comparison of estimates based on cell phone interviews with faceto-face interviews, World Health OrganizationLebanon office.

[16] World Health Organization, 2008, Executive summary: 2008-2013 Action Plan for the Global Strategy for the Prevention and Control of Non communicable Diseases Report 2008, World Health Organization, Date of access: 30/4/2021. https://www.who.int/nmh/publications/ncd_action_p lan_en.pdf.

[17] Cooper R.S., Amoah A.G., and Mensah G.A., 2003, High blood pressure: the foundation for epidemic cardiovascular disease in African populations, Ethn Dis., 13, 48 - 52.

[18]Bonita R., Beaglehole R., and Kjellström T., 2006, Basic epidemiology, $2^{\text {nd }}$ edition, World Health Organization, Date of access: 3/4/2020. https://apps.who.int/iris/bitstream/handle/10665/435 41/9241547073_eng.pdf?sequence=1\&isAllowed=y. [19] Akinlua J.T., Meakin R., Umar A.M, and Freemantle N., 2015, Current Prevalence Pattern of Hypertension in Nigeria: A Systematic Review, PLoS ONE, 10, 0140021.

[20] Ogah O. S., and Rayner B.L., 2013, Recent advances in hypertension in sub-Saharan Africa. Heart, 0, 1 - 8. https://Doi:10.1136/heartjnl-2012303227.

[21]Federal Ministry of Health of Nigeria, 2015, National Strategic Plan of Action on Prevention and Control of Non-Communicable Diseases, Federal Ministry of Health - Nigeria, Date of access: $12 / 6 / 2018$.

www.medbox.org/Nigeria-national...prevention-andcontrol...noncommunicablediseases.pdf.

[22] Dalal S., Beunza J.J., Volmink J., Adebamowo C., Bajunirwe F., Njelekela M., et al., 2011, noncommunicable diseases in sub-Saharan Africa: what we know now. Int J Epidemiol., 40: 885-901.

[23] Groves J., 2010, International Alliance of Patients' Organizations perspectives on personcentered medicine. International Journal of Integrated Care, 10, 27-29. ISSN 1568-4156. URL: http://www.ijic.org.
[24] Roy M., Levasseur M., Couturier Y., Lindströme B., and Généreux M., 2015, The relevance of positive approaches to health for patient-centered care medicine. Preventive Medicine Reports, 2, 10 - 12. http://dx.doi.org/10.1016/j.pmedr.2014.11.005.

[25]Chawla N.V., and Davis D.A., 2013, Bringing Big Data to Personalized Healthcare: A PatientCentered Framework. J Gen Intern Med, 28(Suppl 3): S660-5. http://DOI:10.1007/s11606-013-2455-8.

[26] Wu F., Narimatsu H., Li X., Nakamura S., Sho R., Zhao G, et al., 2017, non-communicable diseases control in China and Japan. Globalization and Health, 13, 91. http://DOI:10.1186/s12992-0170315-8.

[27] World Health Organization, 2020, Assessing national capacity for the prevention and control of non-communicable diseases: report of the 2019 global survey, World Health Organization, Date of access:

14/3/2021.https://www.who.int/publications/i/item/n cd-ccs-2019.

[28] United Nations, 2011, Draft Resolution Submitted by the President of the General Assembly: Political declaration of the High-level Meeting of the General Assembly on the Prevention and Control of Non-Communicable Diseases, United Nations, Date of access: 30/4/2021.

https://www.who.int/nmh/events/un_ncd_summit20 11/political_declaration_en.pdf.

[29] World Health Organization, 2009, Milestones in Health Promotion: Statements from Global Conferences, World Health Organization, Date of access: 30/4/2021.

https://www.who.int/healthpromotion/Milestones_H ealth_Promotion_05022010.pdf.

[30] World Health Organization, 2004, National Action Plan for Prevention and Control of NonCommunicable Diseases and Health Promotion in Pakistan: A Public-Private Partnership in Health, World Health Organization, - WHO Report 2004; 1 -141 .

[31] Okafor C.N., Young E.E., Nwobi A.E., 2016, Health promotion strategies for the prevention and control of non-communicable diseases in Nigeria. South American Journal of Public Health, 4(1), 1 10 . 